\title{
Establishing collagen quality criteria for sulphur isotope analysis of archaeological bone collagen
}

\author{
Olaf Nehlich • Michael P. Richards
}

Received: 25 October 2008 / Accepted: 5 February 2009/Published online: 26 February 2009

(C) Springer-Verlag 2009

\begin{abstract}
Sulphur isotope measurements of bone collagen from archaeological sites are beginning to be applied more often, yet there are no clear criteria to assess the quality of the collagen and therefore the validity of the sulphur isotope values. We provide elemental data from different methods (DNA sequences, amino acid sequences and mass spectrometric measurements) which are used to establish a reliable system of quality criteria for sulphur isotope analyses of bone collagen. The difference in the amount of sulphur from fish and mammalian collagen type I led to the suggestion to use different criteria to assess the in vivo character of the collagen between these two categories. For establishing quality ranges, the bone collagen of 140 modern animals were analysed. The amount of sulphur in fish and mammalian bone collagen is $0.63 \pm 0.08 \%$ and 0.28 $\pm 0.07 \%$, respectively. Based on these results we define for mammalian bone collagen an atomic C:S ratio of $600 \pm 300$ and an atomic N:S ratio of $200 \pm 100$, and for fish bone an atomic C:S ratio of $175 \pm 50$ and an atomic N:S ratio of $60 \pm$ 20 . These quality criteria were then applied to 305 specimens from different archaeological contexts.
\end{abstract}

Keywords Sulphur isotope $\cdot \mathrm{d} 34 \mathrm{~S} \cdot$ Bone collagen · Quality marker·Sulphur content

O. Nehlich $(\bowtie) \cdot$ M. P. Richards

Department of Human Evolution,

Max-Planck Institute for Evolutionary Anthropology,

Deutscher Platz 6,

04103 Leipzig, Germany

e-mail: olaf@nehlich.com

M. P. Richards

Department of Archaeology, Durham University,

South Park Road,

Durham DH1 3LE, United Kingdom

\section{Introduction}

Sulphur isotope analysis on archaeological bone material has been increasingly applied in archaeology (Richards et al. 2001; Craig et al. 2006; Privat et al. 2007), largely due to technical advances in mass spectrometry, namely on-line continuous flow (Giesemann et al. 1994) which allowed the use of relatively small amounts of collagen. Sulphur isotopes of human bone collagen can be used to address questions of archaeological importance. For example, sulphur isotope ratios can be used to distinguish between freshwater and terrestrial ecosystems, especially when measured together with carbon and nitrogen isotope ratios. Also, sulphur isotope ratios can discriminate between the consumption of foods from different geographical regions, and so can be used within a given population to identify immigrants, again when used in conjunction with other isotopic measurements.

It is therefore important to establish criteria to validate the results of sulphur isotopic measurements of bone collagen, especially as the method is applied more often. In bone, collagen type I is the most abundant protein and commonly used for reconstructing palaeodiet (Ambrose 1990). Collagen type I is a triple helix (Ramachandran et al. 1968; Bornstein and Traub 1979; Piez 1976) and contains two alpha 1 and one alpha 2 helices (Piez 1984). The alpha 1 and alpha 2 chains differ only slightly and consist mainly of triplets with the order Gly-X-Y (where X stands for proline and $\mathrm{Y}$ for hydroxyproline); all other amino acids are less well represented (Piez 1976). The intracellular translated and post-translationally modified collagen fibres are transported into the intercellular space and are then organised into fibrils (Reddi 1984). In bone, the extracellular collagen is embedded in the mineral phase (Veis 1984) and there it can be preserved for a long time either 
unaltered or only slightly altered (Ambrose 1990; DeNiro and Weiner 1988). For archaeological studies, it is necessary to determine the integrity of the analysed material. DeNiro (1985) introduced the use of the atomic $\mathrm{C}: \mathrm{N}$ ratio (2.9-3.6) as a measure of quality for carbon and nitrogen analyses of bone collagen. Ambrose (1990) and DeNiro and Weiner (1988) analysed modern species to generate acceptable ranges of carbon and nitrogen contents. Acceptable quality markers for ancient bone collagen were also published by van Klinken (1999). If a bone collagen has a ratio outside of this acceptable range, this is likely due to the loss of glycine (the most abundant amino acid in collagen) or the addition of nitrogen due to microbial processes. Therefore, most palaeodietary studies rely on these values to indicate the unaltered nature of the extracted bone collagen for carbon and nitrogen isotopic measurements. There are similar issues for sulphur isotope analysis. First, a possible source of additional sulphur is from the burial environment itself. Inorganic sulphates or sulphur compounds from the soil (e.g. gypsum nodules, pyrites or sulphates) can add sulphur to the extracted biomolecules which therefore result in higher sulphur contents. Another source of alteration can be the microbial catalysis of sulphur-containing amino acids of the organic matrix and resulting loss of sulphur. For the isotopic ratios, additional sulphur from the soil is much more of a concern because of a possible shift towards the sulphur isotope ratio of the burial environment meaning that the measured value will not represent the in vivo value. Therefore, we propose the use of a similar measurement as is used in carbon and nitrogen isotope analysis, specifically the reporting of the amount of sulphur in a sample as well as a comparison between the sulphur amounts in the extracted bone collagen compared with the amounts of carbon and nitrogen (C:S and $\mathrm{N}: \mathrm{S}$ ratios). Although few published studies address the problem of quality control of sulphur isotope analysis, there is still neither an accepted range for sulphur contents nor other reliable markers available. Additionally, the number of published analysed specimen is statistically very low (less than 150 in total). Here, we summarise these previous studies and provide results from our own unpublished studies to suggest quality control indicators for sulphur isotope measurements of archaeological bone collagen.

\section{Previous research}

There have been only a few published studies that have assessed the amount of sulphur in bone collagen as an indicator of the preservation quality of the analysed material (Richards et al. 2001; Craig et al. 2006; Privat et al. 2007). Richards et al. (2001) presented the first measurements of direct analysed ancient bone collagen using continuous flow mass spectrometry. Richards et al. (2001) argued for the use of C:S (and N:S) ratios to verify the integrity and in vivo character of the collagen molecules. Their measurements yielded C:S ratios of $494 \pm$ 128. Based on calculations using published amino acid sequences, they determined the amount of sulphur in bone collagen to be $0.16 \%$, which was also the value determined by Leach (2003). Another approach for calculating theoretical sulphur percentages in collagen type I was suggested by Craig et al. (2006). Here, published DNA sequences from genetic databases of different mammalian species were used to calculate the amount of sulphur containing amino acids and the percentage of sulphur. The theoretic average ratio found for dogs (Canis familiaris) and humans (Homo sapiens) was 548 and 605 for the C:S ratio and 177 and 189 for the N:S ratio, respectively. The analysed animals (dog, grey seal and red deer) had sulphur amounts of $0.22 \pm 0.02 \%$, and therefore had C:S and N:S ratios of $496 \pm 39$ and $148 \pm 12$, respectively. Privat et al. (2007) analysed modern (humans, cow and fish) and ancient species for comparison and assessment of sulphur amounts. The resulting $\mathrm{C}: \mathrm{S}$ and $\mathrm{N}: \mathrm{S}$ ratios for the modern specimens were $278 \pm 104$ and $88 \pm 33$, and for the archaeological samples $394 \pm 117$ and $121 \pm 36$, respectively. Therefore, they argue that samples with sulphur amounts above $0.60 \%$ and C:S ratio below 200 and N:S ratio below 60 should be excluded. The aim of this present study is to obtain exact ranges for the quality control of sulphur measurements using many more modern samples from a range of species.

\section{Methods}

Bone collagen was extracted following the procedures described in Richards and Hedges (1999) and Brown et al. (1988). The bone surface was cleaned by air abrasion with $\mathrm{Al}_{2} \mathrm{O}_{3}$, cut into a piece with a mass of 500-700 mg and then demineralised in $0.5 \mathrm{M} \mathrm{HCl}$ for several days at $4^{\circ} \mathrm{C}$. The demineralised bone was heated at $70^{\circ} \mathrm{C}$ for $48 \mathrm{~h}$ and then EZEE filtered and ultrafiltered (cut-off $30 \mathrm{kDa}$ ). The resulting filtrate was freeze-dried. This procedure was applied to all analysed bone samples, both modern and ancient.

Approximately $0.5 \mathrm{mg}$ collagen was weighed into a tin capsule for carbon and nitrogen isotopic measurements. The sample was combusted in a Flash EA 2112 coupled to a Delta XP (Thermo-Finnigan ${ }^{\circledR}$, Bremen, Germany) at the Max-Planck Institute for Evolutionary Anthropology in Leipzig (Germany). The resulting isotopic ratio has an error better than $\pm 0.1 \%$ and the error for the calculated amount percent is less than $5 \%$.

To analyse sulphur isotopes $10 \mathrm{mg}$ of mammalian/avian bone collagen and $6 \mathrm{mg}$ of fish bone collagen were 
weighed out and mixed with $1 \mathrm{mg}$ of $\mathrm{V}_{2} \mathrm{O}_{5}$ (Microanalysis, U.K.) to catalyse the combustion and reduce the variability (Morrison et al. 2000). The material was then combusted in a Heka EuroVector elemental analyser (HeKaTech, Wegberg, Germany) and analysed in a Thermo-Finnigan Delta V plus (Giesemann et al. 1994; Kester et al. 2001). The combustion takes place at $1,010^{\circ} \mathrm{C}$ and the resulting gases are reduced over hot copper $\left(\sim 800^{\circ} \mathrm{C}\right)$ to minimize the amount of $\mathrm{SO}_{3}$ (Ueda and Krouse 1986). The gases are transported via a helium flow of $\sim 95 \mathrm{ml} / \mathrm{min}$ and separated on a GC column (Poropak $0.8 \mathrm{~m}$ at $84^{\circ} \mathrm{C}$; see Yun et al. 2005) and then channelled into the mass spectrometer via a ConFlo III. The $\mathrm{N}_{2}$ and $\mathrm{CO}_{2}$ gases are diluted out with helium gas and only $\mathrm{SO}$ and $\mathrm{SO}_{2}$ gases are analysed at the masses 48, 50, 64 and 66 . The $\delta^{34} \mathrm{~S}$ value is measured against a sulphur gas standard and corrected for oxygen isotope mass variations (Coleman 2004; Fry et al. 2002). A daily run of ten collagen samples is accompanied by the inorganic international standards NBS127 (20.3\%), IAEAS1 (-0.3\%), IAEA-S2 (21.5\%) and IAEA-SO-5 (0.5\%) (Coplen and Krouse 1998) and two organic standards: NIST bovine liver $1577 \mathrm{~b}$ (7.5\%) (Fry et al. 2002) and IVA protein casein $(6.3 \%)$. The precision of the analyses for the standards (organic and inorganic) are better than $\pm 0.4 \%$ o with a standard deviation $(\sigma)$ of better than $0.3 \%$. Four internal bone collagen standards (several extractions from the same bone of two pigs and two cows) were run daily within the runs and resulted in a standard deviation of $\pm 0.8 \%$ o $(n=$ 123). Within a daily run, only ten samples of bone collagen can be analysed to avoid biases in the isotopic results, because of the increase of background noises in the mass spectrometer and heavy usage of the filament. The bone collagen samples run in duplicates on different days have differences of $\pm 0.6 \%$ or better. The amount of sulphur was calibrated daily against the inorganic standards with a resulting error of better than $10 \%$.

\section{Materials}

To calculate the theoretical sulphur contents (weight percent) of collagen type I from different species, several published amino acid profiles and DNA/protein sequences were collected and the weight percent of the elements of interest were calculated based on the amino acid contents (see Appendix for details). The DNA sequence for collagen type I of modern collagen should not vary much from the collagen sequences of ancient specimens. The protein database SwissProt contains nine complete modern collagen type I sequences (separate sequences of alpha 1 and alpha 2 chains) of different species (as of August 2008). Table 1 lists the species by Latin name with their taxonomic class and family with the Swiss-Prot ID number. There are minor post-

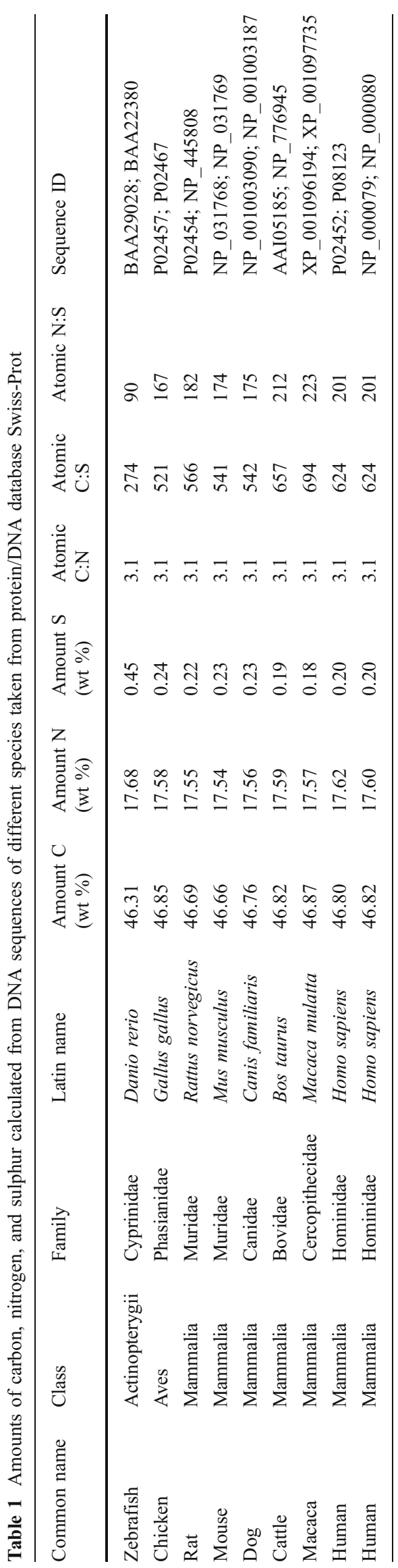




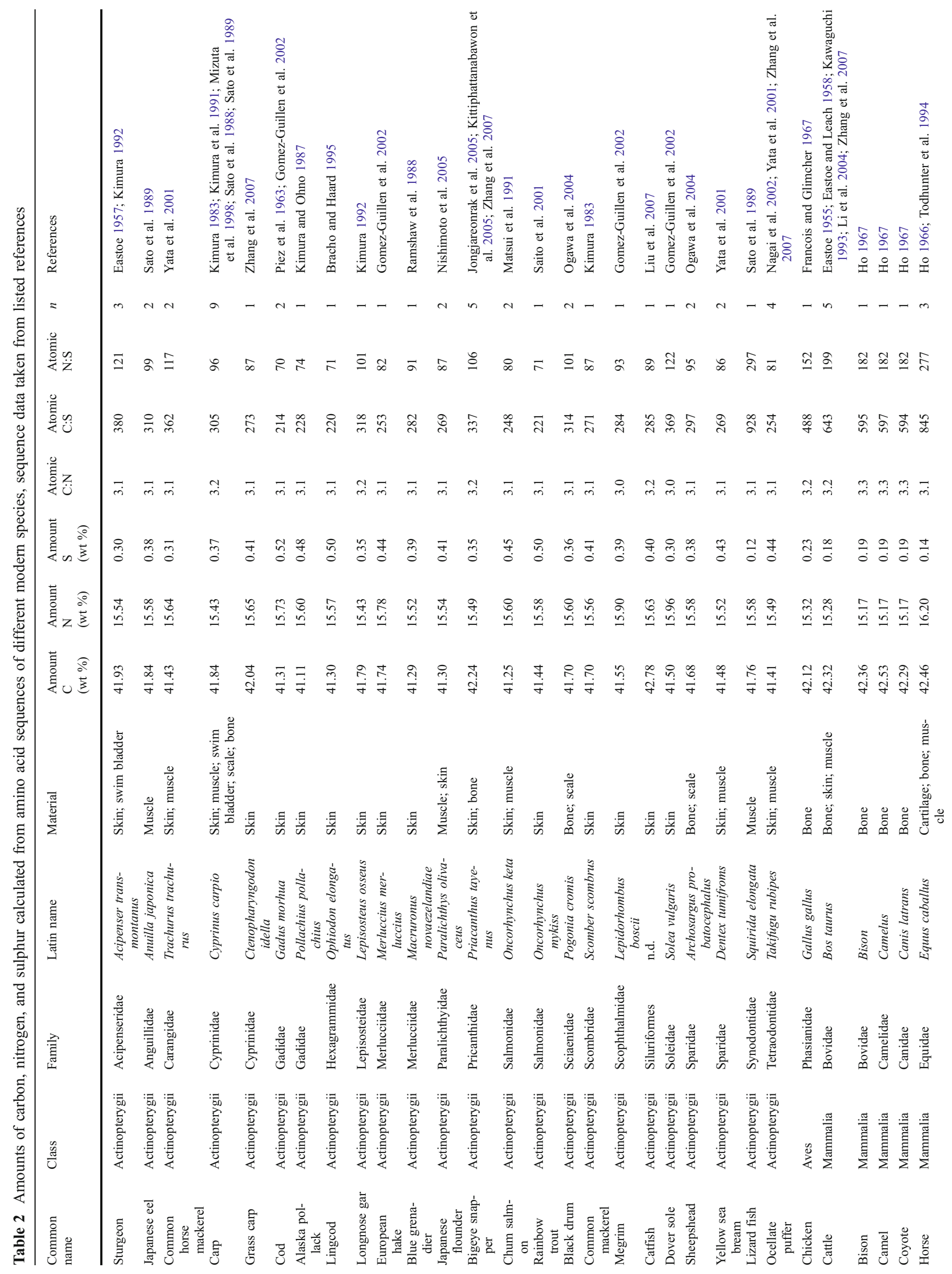


translational changes in structure (Piez 1984) which are not taken into account for the calculation of the weight percentages. Therefore, differences may occur between sequences from DNA compared to amino acid contents of extracted collagen type I from animal tissues. For comparison, amino acid sequences of collagen type I were collected of three classes of modern animals (Actinopterygii, Aves, and Mammalia). Thirty-nine modern and 15 Pleistocene species were collected (all 54 amino acid sequences are listed in Tables 2 and 3 with references). The calculated amounts of carbon, nitrogen and sulphur were used for comparison with data obtained by isotopic mass spectrometry of modern and ancient bone collagen.

A range of modern and ancient bone collagen of different species was analysed by mass spectrometry. The results from the modern samples are listed in Tables 4 and 5 show the mean values per species of the ancient samples grouped into time periods.

\section{Results and discussion}

The calculated amounts of carbon, nitrogen and sulphur from DNA sequences and published amino acid sequences are listed in Tables 1,2 and 3. For the DNA sequences the average amount of carbon and nitrogen is 46.7 and $17.6 \mathrm{wt}$ $\%$, respectively. However, the amount of sulphur differs between these specimens at the taxonomic level where the mean value of fish collagen type I (Actinopterygii) is $0.45 \mathrm{wt} \%$, for birds (Aves) it is $0.24 \mathrm{wt} \%$, and for mammals (Mammalia) it is $0.21 \mathrm{wt} \%$ (Fig. 1). This is also evident in amino acid sequences taken from the literature (modern specimens). Here the amount of carbon and nitrogen is generally lower (carbon $42.1 \mathrm{wt} \%$, nitrogen $15.4 \mathrm{wt} \%$ ), but the difference in the amount of sulphur remains (fish 0.38 wt $\%$, birds 0.23 wt $\%$, mammals 0.18 wt \%), shown in Fig. 2.

As can be seen (Fig. 3), there are signs of collagen degradation in the ancient bone collagen and the average sulphur amount decreases from the modern to prehistoric samples. The number of methionine residues is greatly decreased, and sometimes no methionine was found at all, and therefore the results are no more reliable than for the in vivo character of the (bone) collagen type I.

Most collagen type I does not contain the sulphurcontaining amino acid cysteine; therefore, the amount of sulphur originates only from methionine. Neumann (1949) concluded that the amount of methionine in collagen type I differs between mammals and fish. Methionine is an essential amino acid for fish, birds and mammals as it is converted within liver tissue to sulphur-adenosylmethionine, which is the main methyl donor in animal tissues (Cantoni 1975). Small parts of the pool of methionine are metabolised 


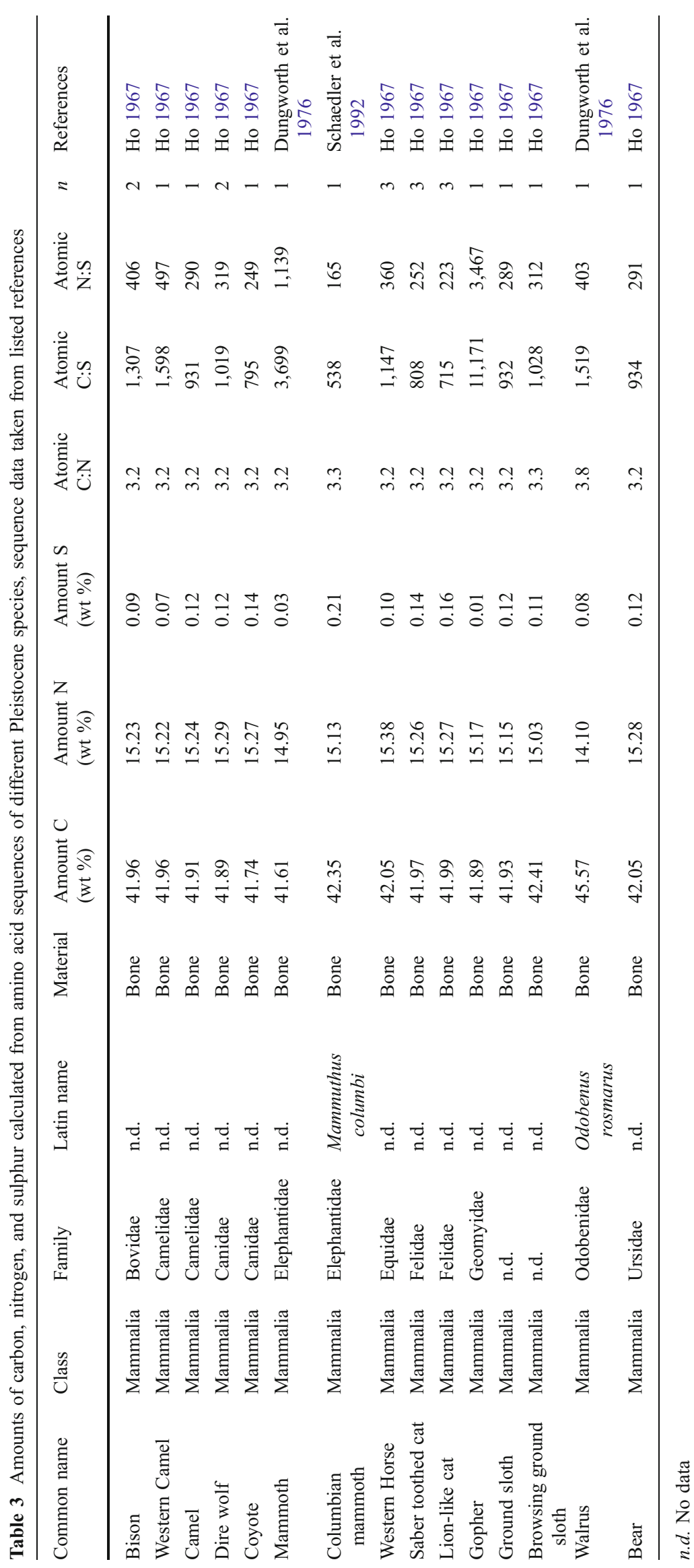




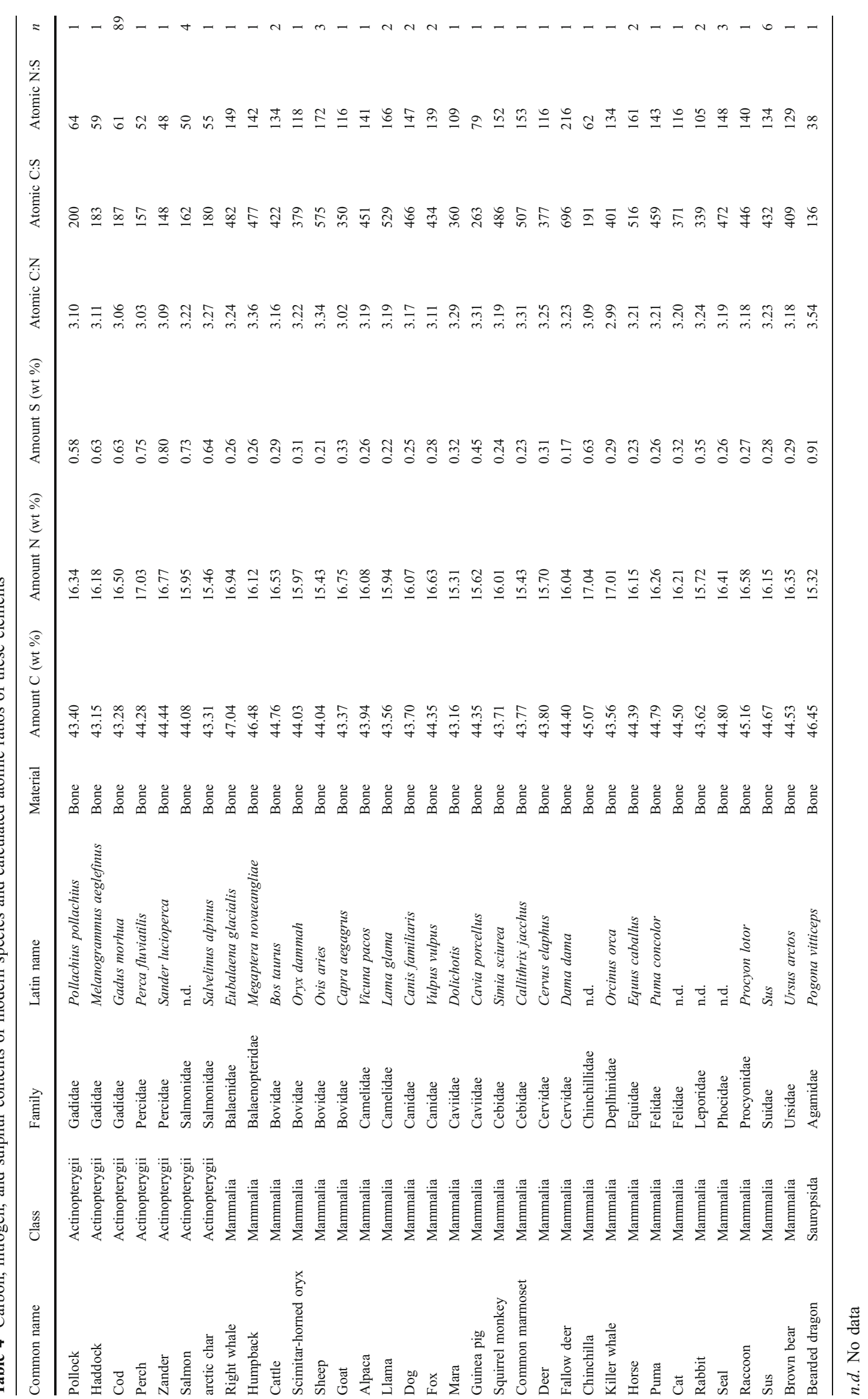




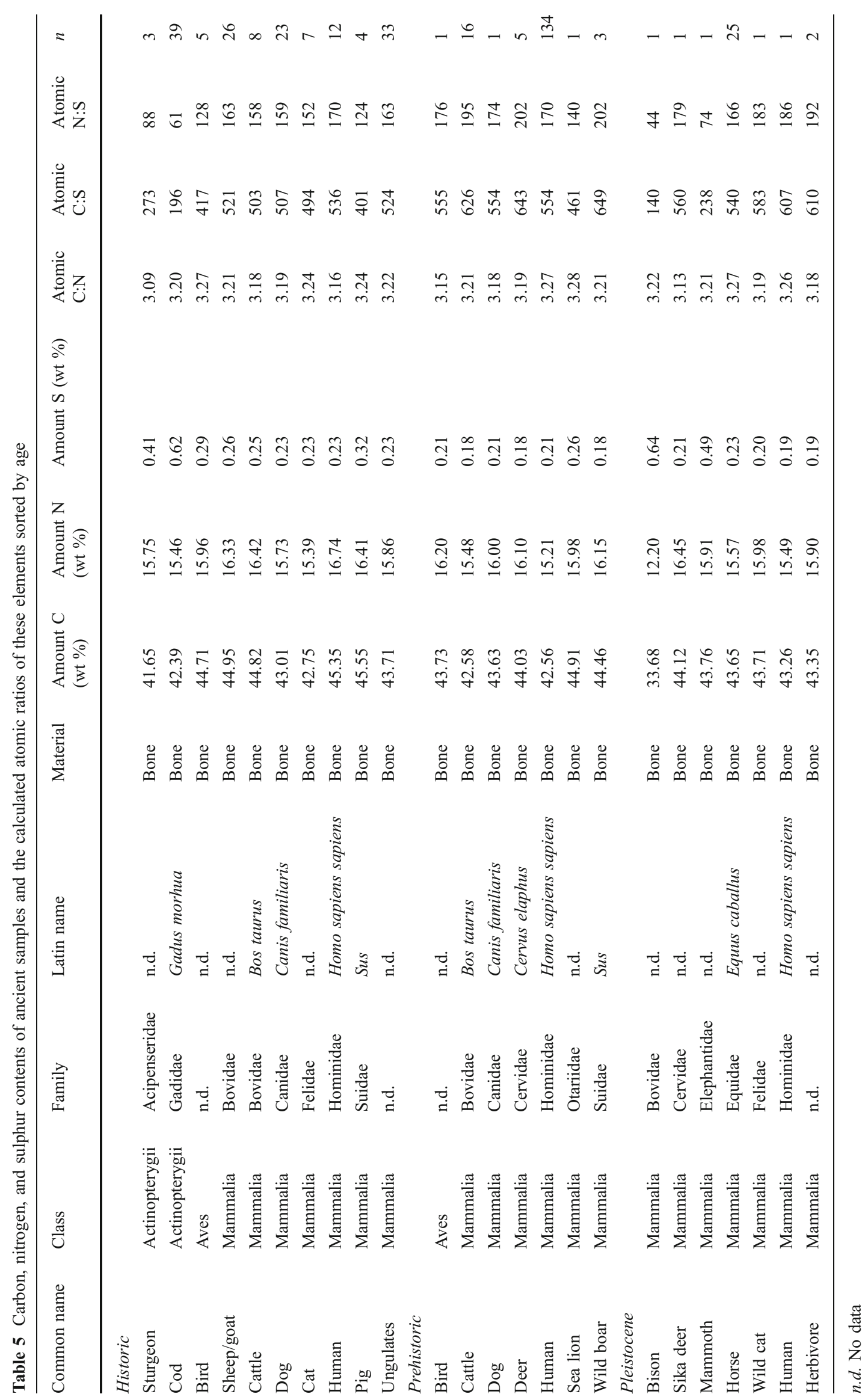




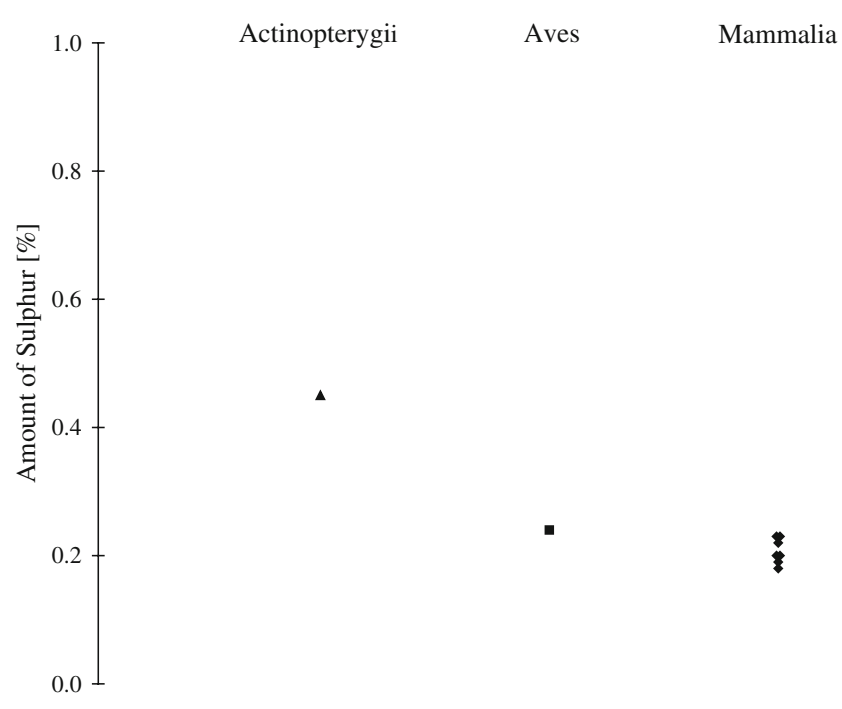

Fig. 1 Theoretical amount of sulphur in collagen type I calculated from DNA sequences based on amino acid composition of chain $\alpha 1$ $(2 \mathrm{x})$ and $\alpha 2(1 \mathrm{x})$

to cysteine or other sulphur-containing molecules (Dziewiatkowski 1962; Finkelstein and Martin 1984; Finkelstein et al. 1988), but within a balanced diet the incorporated methionine should be added to the methionine pool without much loss. Therefore, the imbedded methionine in collagen type I originates from dietary methionine (dietary protein; Ambrose and Norr 1993), but the amount of methionine residues within the collagen triple helix is determined by the genetic sequence. In accordance with the genetic sequences, the amino acid sequences of the modern specimens show a similar pattern in the amount of sulphur between fish and mammalian collagen type I (Table 6). Additionally, the amount of carbon and nitrogen differs between these sources of information (DNA sequences vs amino acid sequences). The calculated amount of carbon and nitrogen is consistently higher in sequences from DNA databases than in amino acid sequences. This seems to be a methodological artefact, but the general pattern holds. Although the differences between the methods are significant, taking into account the analytical error for amino acid analysis the absolute values differ only minorly. Both theoretical datasets are problematic; the DNA sequence will be altered post-translationally, and the extraction of collagen type I for the amino acid sequences adds another systematic error of gain or loss of collagenous material. Furthermore, the data of published amino acid sequences are biased as there is a huge variety of extraction methods for collagen type I. But, even with all these uncertainties, the data support the absolute differences in the amount of sulphur between collagen type I of mammals and fish. As shown in Table 6, there are differences between the theoretical and measured data possibly due to methodological errors. Reasons for the observed effect might be additional water bound to the molecule or post-translational changes which are not calculable from DNA sequences.

To avoid methodological biases, we tested if these theoretical considerations hold true by applying mass spectrometry to modern bone collagen extracted following the standard archaeological protocol (see above). The results are given in Table 4, and a summary by species, mean values per class, method and dating are given in Table 6. Most specimens were run at least in duplicate. Figure 3 shows the results of the mass spectrometric sulphur measurements for each specimen. Archaeological bone collagen type I was analysed in comparison to modern bone collagen, to estimate the influence of the burial environment onto the sulphur content in the organic part of the bone. For modern bone collagen from fish, birds and mammals, the median values of the amount of sulphur are $0.61,0.27$ and 0.27 wt \%, respectively. Bird and mammalian bone collagen are very similar and therefore will be combined for further analyses of the data, because there are only a few samples of birds, too few for a statistical analysis. The only sample of a saurian species (bearded dragon) was excluded, but shows very interesting results, as discussed below. There is no significant difference in the amount of carbon in fish and mammalian bone collagen, but the amount of nitrogen and sulphur differs significantly (Table 7). The sensitivity to outliers makes the statistical analysis problematic and, because we are not dealing with Gaussian distributed results, all significances are biased. The Mahalanobis distance as a robust measure for the difference (De Maesschalck et al. 2000) can detect statistic significant variance within a dataset with a number of outliers. The analyses of the measured modern samples revealed very small differences in carbon and nitrogen, but not in sulphur. Below a certain threshold, the difference is not significant in a robust sense; this is the case for the amounts of carbon and nitrogen. The amount of sulphur differs signifi-

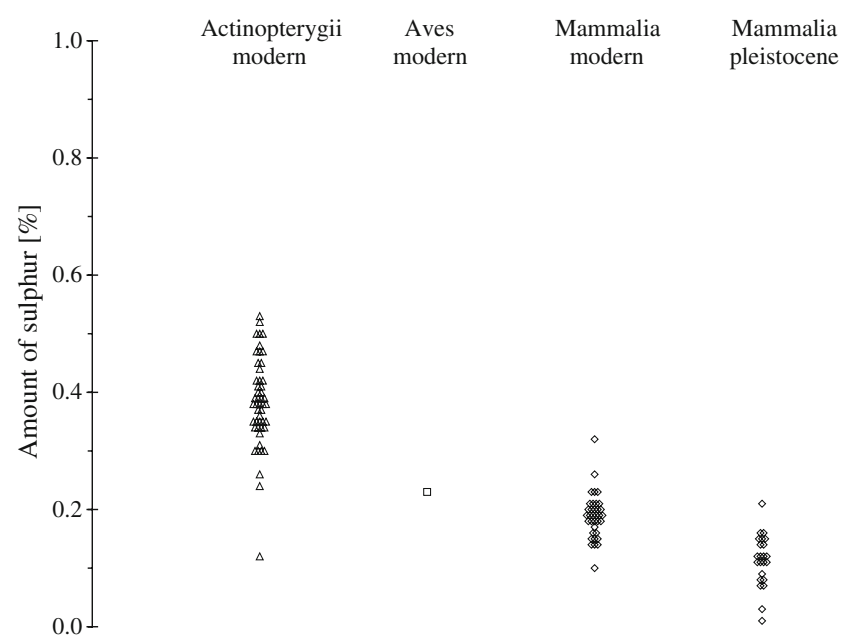

Fig. 2 Theoretical amount of sulphur in collagen type I calculated from amino acid sequences of published chemical protein analyses 
Fig. 3 Amount of sulphur in bone collagen analysed by mass spectrometry. Results are grouped by class of animals and the time periods they originate from

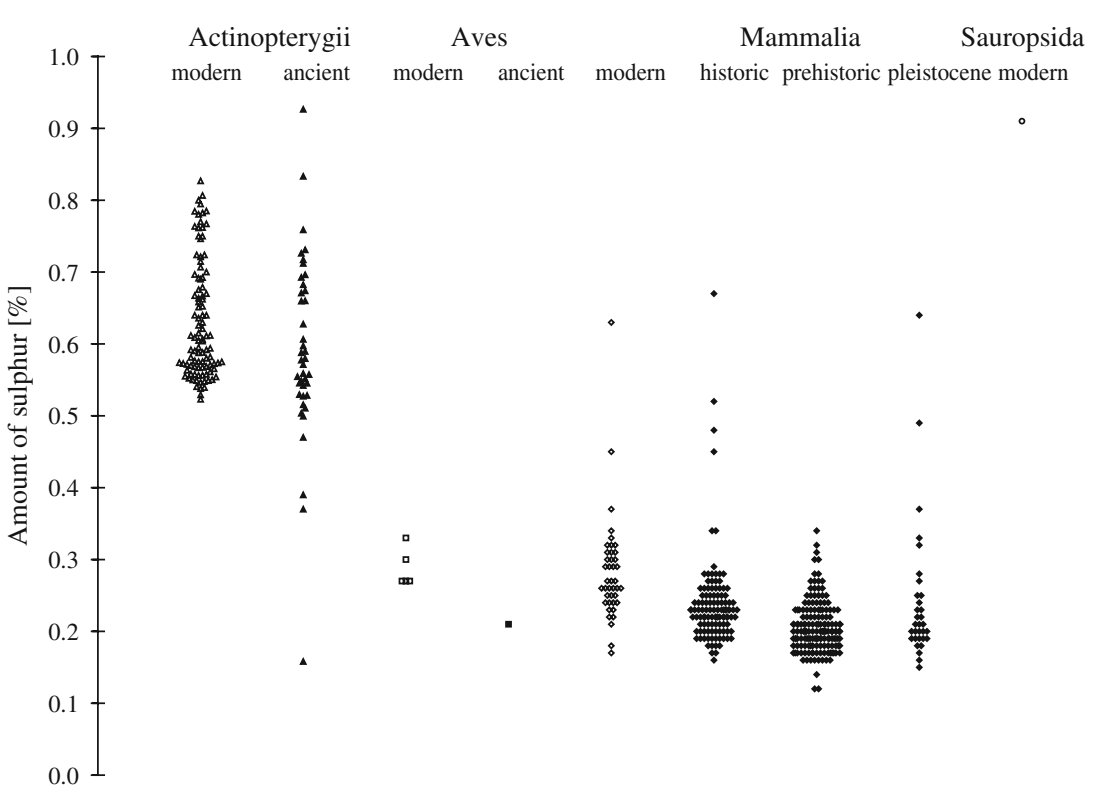

cantly and consistently between fish and mammalian bone collagen; therefore, it is necessary to validate the sulphur data of fish and mammalian bone collagen differently.

For the modern mammals, the amount of sulphur in bone collagen ranges absolutely from 0.17 to $0.63 \mathrm{wt} \%$, but the $95 \%$ confidence interval ranges only from 0.19 to $0.32 \mathrm{wt} \%$ (average: $0.28 \pm 0.07$ ). Because of possible loss or gain of material in archaeological bone collagen, this range should be expanded from 0.15 to $0.35 \mathrm{wt} \%$ (Fig. 3). The suggested range is taken from the $95 \%$ confidence interval combined with the average value and standard deviation in order to ensure adaptability to many different extraction methods and equipment between different laboratories. The calculation of atomic C:S and atomic N:S ratios (suggested by Richards et al. 2001, following DeNiro 1985) result in acceptable ranges for modern mammalian bone collagen from 313 to 696 and 111 to 216 , respectively, when specimens with atomic $C: N$ ratios below 2.9 or above 3.6 (the acceptable ranges for bone
Table 6 Mean values of the amount of carbon, nitrogen, and sulphur in fish (Actinopterygii) and mammals (Mammalia) determined by different methods (calculated from DNA and amino acid sequences and measured by mass spectrometry). Results are divided into time periods and origin

n.d. No data

\begin{tabular}{|c|c|c|c|c|}
\hline Time period & Element & Method & Actinopterygii & Mammalia \\
\hline \multirow[t]{9}{*}{ Modern } & \multirow[t]{3}{*}{ Carbon } & DNA & $46.31 \%(1)$ & $46.78 \pm 0.07 \%$ \\
\hline & & Amino acid & $41.70 \pm 0.40 \%$ & $42.43 \pm 0.92 \%$ \\
\hline & & Mass spectrometry & $43.34 \pm 0.43 \%$ & $44.41 \pm 0.86 \%$ \\
\hline & \multirow[t]{3}{*}{ Nitrogen } & DNA & $17.68 \%(1)$ & $17.58 \pm 0.03 \%$ \\
\hline & & Amino acid & $15.56 \pm 0.12 \%$ & $15.44 \pm 0.46 \%$ \\
\hline & & Mass spectrometry & $16.47 \pm 0.42 \%$ & $16.15 \pm 0.51 \%$ \\
\hline & \multirow[t]{3}{*}{ Sulphur } & DNA & $0.45 \%(1)$ & $0.21 \pm 0.02 \%$ \\
\hline & & Amino acid & $0.38 \pm 0.08 \%$ & $0.19 \pm 0.04 \%$ \\
\hline & & Mass spectrometry & $0.63 \pm 0.08 \%$ & $0.28 \pm 0.07 \%$ \\
\hline \multirow[t]{3}{*}{ Historic } & Carbon & Mass spectrometry & $42.34 \pm 1.53 \%$ & $44.11 \pm 2.11 \%$ \\
\hline & Nitrogen & Mass spectrometry & $15.48 \pm 0.57 \%$ & $16.07 \pm 0.83 \%$ \\
\hline & Sulphur & Mass spectrometry & $0.60 \pm 0.15 \%$ & $0.24 \pm 0.07 \%$ \\
\hline \multirow[t]{3}{*}{ Prehistoric } & Carbon & Mass spectrometry & n.d. & $42.67 \pm 2.68 \%$ \\
\hline & Nitrogen & Mass spectrometry & n.d. & $15.29 \pm 1.09 \%(160)$ \\
\hline & Sulphur & Mass spectrometry & n.d. & $0.21 \pm 0.04 \%$ \\
\hline \multirow[t]{6}{*}{ Pleistocene } & \multirow[t]{2}{*}{ Carbon } & Amino acid & n.d. & $42.14 \pm 0.75$ \\
\hline & & Mass spectrometry & n.d. & $43.32 \pm 2.04 \%$ \\
\hline & \multirow[t]{2}{*}{ Nitrogen } & Amino acid & n.d. & $15.19 \pm 0.27 \%$ \\
\hline & & Mass spectrometry & n.d. & $15.54 \pm 0.78 \%$ \\
\hline & \multirow[t]{2}{*}{ Sulphur } & Amino acid & n.d. & $0.11 \pm 0.04 \%$ \\
\hline & & Mass spectrometry & n.d. & $0.24 \pm 0.10 \%$ \\
\hline
\end{tabular}


Table 7 Statistical analysis of the amount of carbon, nitrogen, and sulphur of fish (Actinopterygii) and mammalian (Mammalia) bone collagen. Results of the Wilks' Lambda test of distribution and Mahalanobis distances tested between the groups Acterinopterygii and Mammalia

\begin{tabular}{lllll}
\hline & \multicolumn{2}{l}{ Wilks' Lambda test } & \\
\cline { 2 - 4 } Element & $\lambda$ & $F$ value & p value & Mahalanobis distance \\
\hline Carbon & 0.994 & 3.071 & 0.080 & 0.031 \\
Nitrogen & 0.942 & 29.940 & $<0.0001$ & 0.300 \\
Sulphur & 0.162 & 2496.019 & $<0.0001$ & 25.043 \\
\hline
\end{tabular}

collagen; DeNiro (1985)) are excluded (Fig. 4). In archaeological material, a similar range from $600 \pm 300$ and $200 \pm 100$, respectively, corresponds to valid data in accordance to the range of the amount of sulphur (Figs. 5 and 6). These ranges expand the ones suggested by Richards et al. (2001) (C:S= $463 \pm 176)$ or Craig et al. (2006) (C:S=496 $\pm 39, \mathrm{~N}: \mathrm{S}=148 \pm$ 12) on a much broader range of animal species and number of specimens. The comparison with Privat et al. (2007) is problematic because there is no distinction between fish and mammalian samples, which confuses the mean values for the atomic $\mathrm{C}: \mathrm{S}$ and $\mathrm{N}: \mathrm{S}$ ratios.

By applying these quality criteria for mammalian and bird bone collagen to archaeological material, it can be observed that only a few samples tend to have higher amounts of sulphur than acceptable. In general, it can be seen that the amount of sulphur in the archaeological samples tends to be decreased compared to modern samples. There are three historic samples in the dataset with too much (by comparison to modern samples) sulphur, and therefore the atomic $\mathrm{C}: \mathrm{S}$ and $\mathrm{N}: \mathrm{S}$ ratios are too low. These results are excluded in the further process of analysing the dataset. Within the prehistoric samples, no obvious outliers were detectable; however, in the Pleistocene samples, again there are two samples outside of the established range. Nevertheless, there is no difference between the archaeological samples, but in the modern samples the amount of sulphur is higher.

The higher amount in modern samples might be a result of additional chondroitin sulphate attached to lysine residues of the modern collagen fibrils (Öbrink et al. 1975). Chondroitin sulphates are polysaccharides and bound in the endoplasmic reticulum to the protein chain. Each molecule can add sulphur to the collagen, when it is not removed completely during the extraction. The chondroitin sulphate connects the mineral phase with the organic collagen fibres (Burger et al. 1962; Schneiders et al. 2008). After demineralising the bone, the chondroitin sulphate can still be bound to the collagen molecules and the additional sugars would be detectable with individual amino acid analysis. During the analysis of carbon and nitrogen of bulk collagen, the contamination with carbon and nitrogen from chondroitin sulphate is not detectable because it is minor. Sulphur analysis is much more sensitive to contamination with additional material, because of the very small amount and direct measurement of one single amino acid (methionine). But no similar effect seems to be visible for archaeological material. During the time of being buried, the short protein attachments are degraded and therefore no longer detectable or measurable. The $\mathrm{pH}$-value of the soil and other environmental influences may disconnect the bonding of chondroitin sulphate and collagen and therefore the small chondroitin sulphate molecules will be lost during ultrafiltration.

The bone collagen of modern fish (class: Actinopterygii) have amounts of sulphur from 0.52 to $0.83 \mathrm{wt} \%$ (Fig. 3). Based on this, an acceptable range for archaeological
Fig. 4 Box plots of the C:N ratios of samples analysed by mass spectrometry. Results are grouped by class of animals and the time periods they originate from

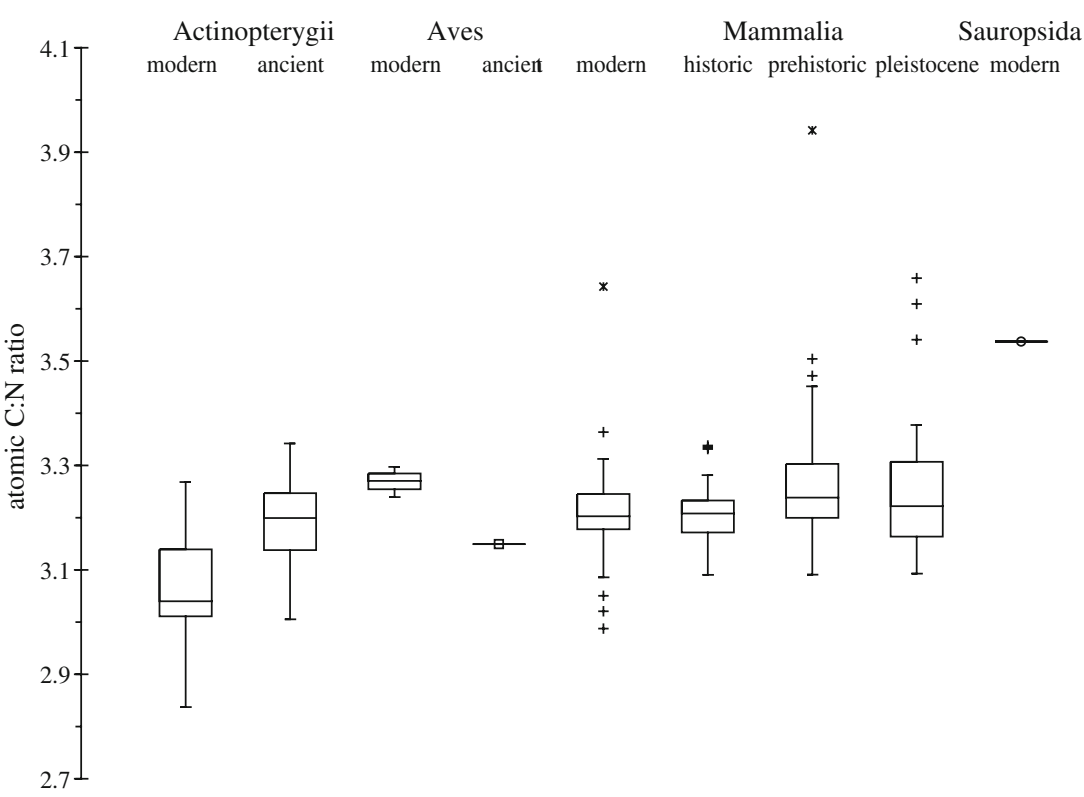


Fig. 5 Box plots of the C:S ratios of samples analysed by mass spectrometry. Results are grouped by class of animals and the time periods they originate from

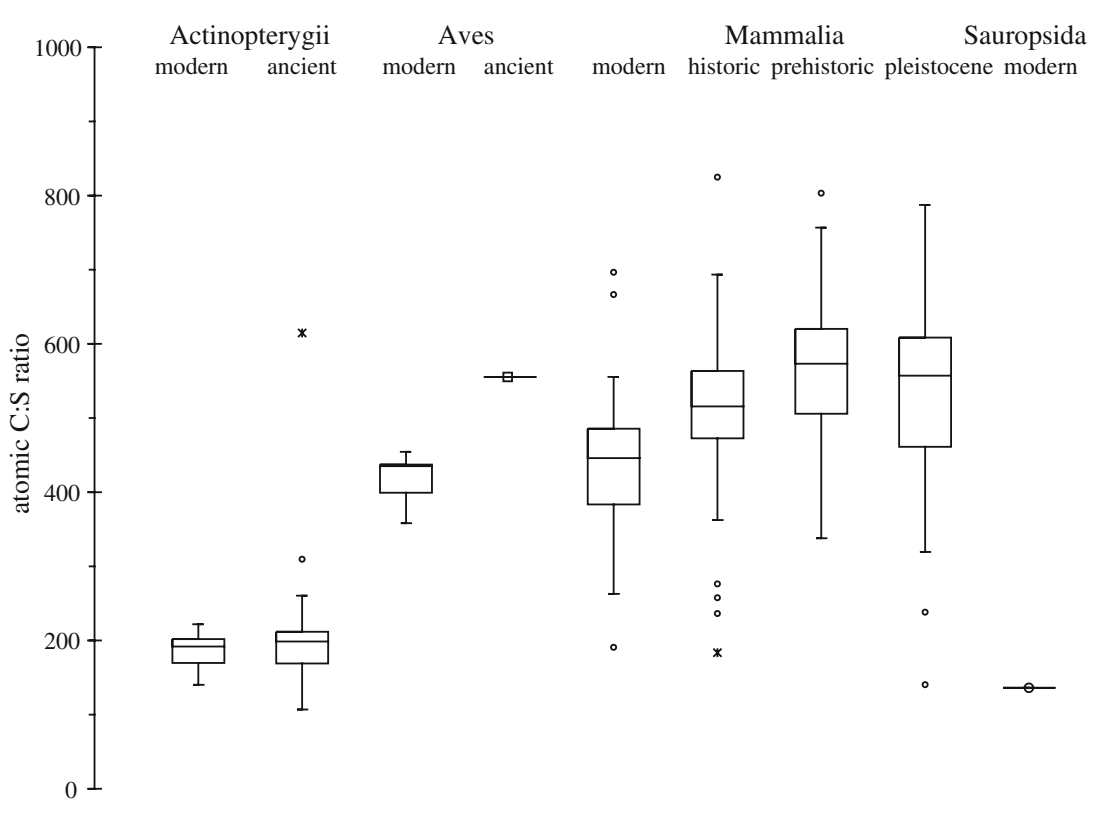

material would be $0.40-0.85 \mathrm{wt} \%$; see above for reasons for expanding the modern range. Comparing the atomic $\mathrm{C}: \mathrm{N}$ ratios of modern fish (Actinopterygii) and mammalian (Mammalia) bone collagen reveal that there is a slight tendency towards lower atomic $\mathrm{C}: \mathrm{N}$ ratios in fish bone collagen. The analysed bone collagen from modern fish bone tends to cluster on the lower end of the acceptable range (DeNiro 1985). The following quality criteria were applied only to specimens within the accepted range of the atomic $\mathrm{C}$ : $\mathrm{N}$ ratio and although the outliers are shown they are excluded from the estimation of acceptable ranges. The calculated atomic $\mathrm{C}: \mathrm{S}$ and $\mathrm{N}: \mathrm{S}$ ratios range from $175 \pm 50$ and $60 \pm 20$, respectively (Figs. 5 and 6). Within the historic fish samples, there are five specimens with sulphur values either too high or too low, and therefore their atomic $\mathrm{C}: \mathrm{S}$ and $\mathrm{N}: \mathrm{S}$ ratio ranges are outside the established range. The comparison of the amounts of sulphur in modern and historic samples shows that there is less variation in the modern samples than in the historic ones. Obviously then, the burial environment greatly influences the sulphur containing amino acids in fish bone collagen. Fish bones are less mineralised and tend to be more easily degraded than mammalian bone collagen. This seems to be a reason for the often observed absence of fish bones in many archaeological sites.

The bone collagen of the bearded dragon, which belongs to the taxonomic class of Sauropodia, displays a very old collagen sequence and is completely different from mammalian bone collagen. It seems that the high amount of
Fig. 6 Box plots of the N:S ratios of samples analysed by mass spectrometry. Results are grouped by class of animals and the time periods they originate from

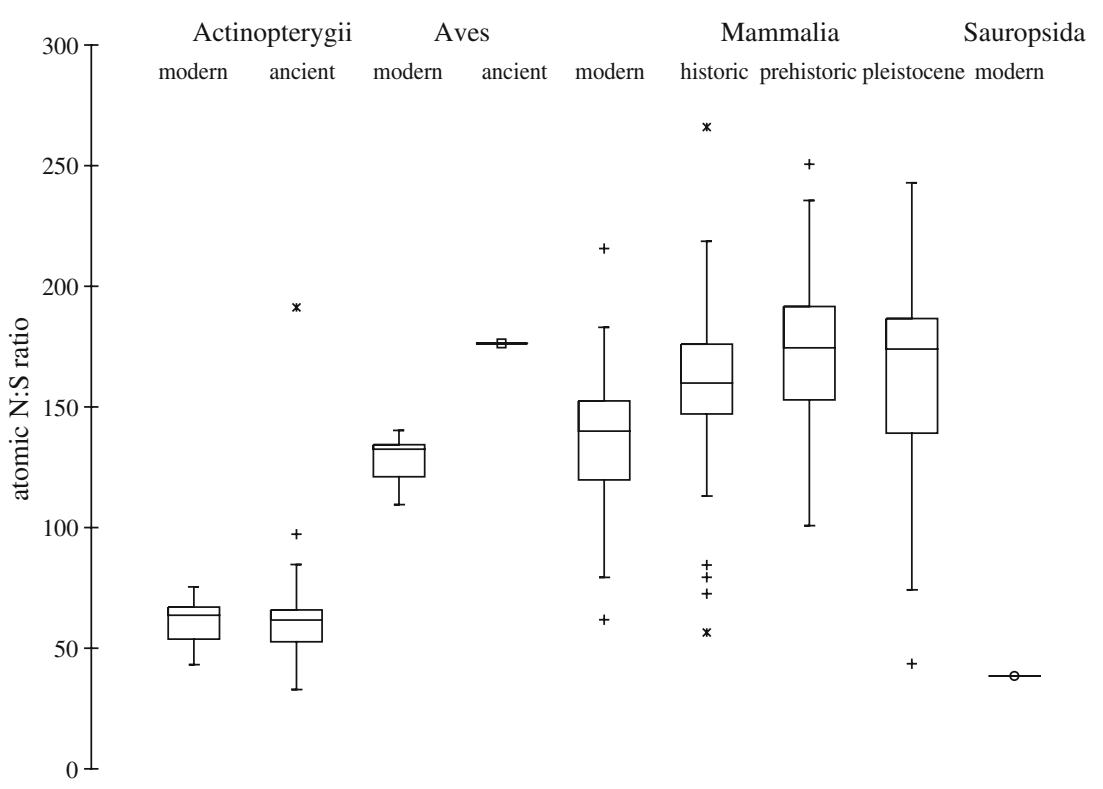


methionine residues in collagen type $\mathrm{I}$ is a very old structural effect. Since there is only limited survival of saurian bones in the archaeological record of the (pre-) historic and Pleistocene period, we do not explore this phenomenon in further detail here.

In Fig. 7, we show the ranges of sulphur isotopic ratios and amounts of sulphur in bone collagen for different classes of animals to demonstrate the power of the method. Marine mammals, like whales and seals from open oceanic waters, and humans and animals living in coastal regions or who consume large amounts of seafood which also have sulphur amounts from 0.15 up to $0.35 \mathrm{wt} \%$, have sulphur isotope ratios ranging from 14 to $19 \%$ (cluster 1 in Fig. 7). Mammals and birds from terrestrial environments (cluster 2 ), whose diets are mainly terrestrial, or freshwater fish based with the same range of sulphur amounts $(0.15-0.35 \mathrm{wt} \%)$, have much lower sulphur isotope values, ranging from $-20 \%$ to $14 \%$. Therefore, a comparison of values from cluster 1 and cluster 2 helps to identify a marine versus a terrestrial diet or inland-originated food from food from marine or coastal regions. For species with higher amounts of sulphur, ranging from 0.4 to $0.8 \mathrm{wt} \%$, to be found in fish from oceanic salt water environments (cluster 3), have sulphur isotope ratios from 14 up to $19 \%$ (or more), while freshwater fish have sulphur isotope ratios ranging from -20 to $14 \%$ (cluster 4 ). The difference in sulphur isotope ratios between cluster 3 and 4 can be used for studying different feeding patterns in estuarine environments.

Mammalian bone collagen with sulphur amounts below 0.15 and above $0.35 \mathrm{wt} \%$ is heavily altered, and therefore does not represent the in vivo structure nor the original sulphur isotope value of the living individual. The most problematic situation for sulphur isotope measurements is the addition of sulphur to the collagen as this must originate from the environment and will have different sulphur isotope values than the bone collagen. The loss of sulphur is less problematic as it will represent only a minor part of the in vivo sulphur containing amino acids in the bone collagen. Fish bone collagen samples with sulphur amounts below 0.4 and above $0.8 \mathrm{wt} \%$ need to be excluded from further examinations. Usually, alterations of the sulphur containing amino acids are more obvious for marine specimens because the isotope values drift significantly towards terrestrial isotope values or seawater sulphate values. All results within these ranges should be seen as representative for the in vivo characteristic of the living organisms.

\section{Conclusion}

The aim of this study was to establish a robust assessment of quality markers to test the suitability of archaeological bone collagen for sulphur isotope analysis. The theoretical calculation of the weight percent sulphur in bone collagen calculated from DNA and amino acid sequences revealed differences in the amount of sulphur between fish and mammalian collagen type I. The calculated amount of sulphur in fish collagen is $0.4 \mathrm{wt} \%$ and for mammalian collagen 0.2 wt $\%$. When we analysed the amount of sulphur in collagen extracted from modern fish and mammalian bone collagen, we determined the sulphur amounts to be $0.63 \pm 0.08$ and $0.28 \pm 0.07 \mathrm{wt} \%$, respectively. Although the measured values for the modern samples are higher in general than the theoretical amounts, we believe that the measured data do represent the accurate in vivo values of the modern animals. It is perhaps possible that the additional sulphur in the modern animals may originate from chondroitin sulphate attached to the collagen type I lysine residues to anchor the fibrils in the mineral
Fig. 7 Scattergram of sulphur isotope ratios versus amount of sulphur of modern samples analysed for this study. Cluster 1 represents sea mammals, cluster 2 terrestrial mammals. Cluster 3 is the range for open sea fish samples and cluster 4 represents freshwater fish values

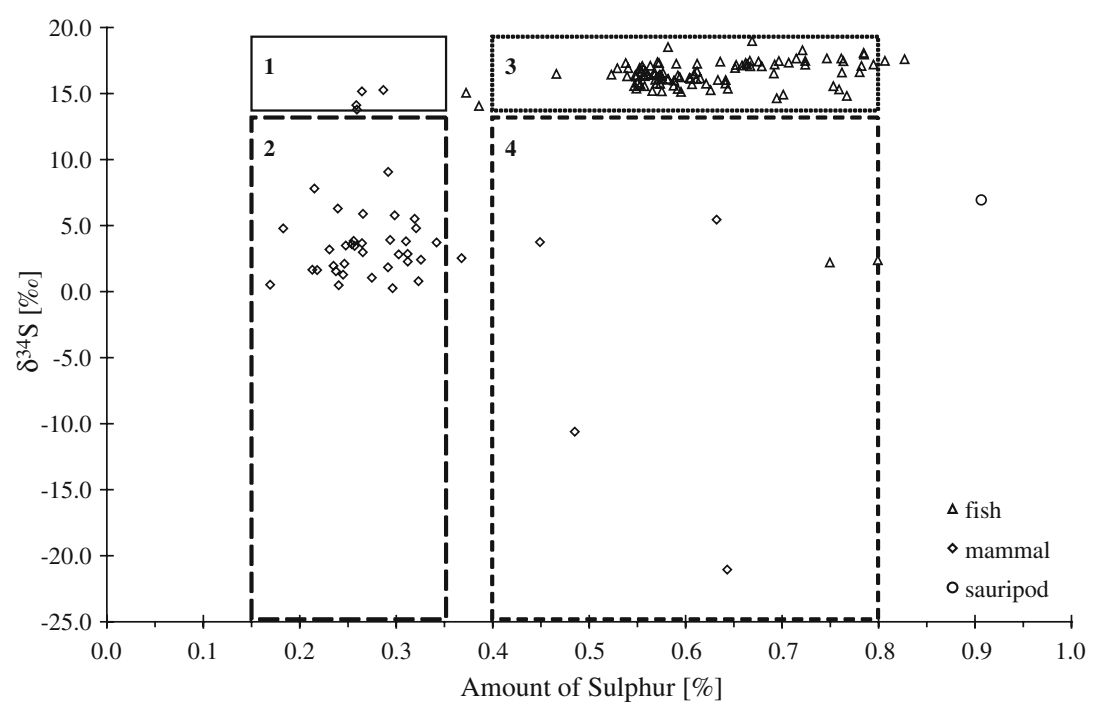


phase of the bone. Based on these results, we suggest the use of different ranges for the quality control of archaeological samples. Specifically, we suggest that the calculated atomic $\mathrm{C}: \mathrm{S}$ ratio for mammalian and bird bone collagen should be between $600 \pm 300$ and for fish bone collagen it should be between $175 \pm 50$. The supposed atomic N:S ratio for mammals and birds is $200 \pm 100$, and for fish $60 \pm 20$.

By applying the calculated marker to archaeological material, we found that it was then possible to exclude obvious outliers and especially to identify samples that contained additional inorganic sulphates. Therefore, we suggest that researchers use the established ranges for sulphur percentages, $\mathrm{C}: \mathrm{S}$ and $\mathrm{N}: \mathrm{S}$ ratios with their own data, as a tool to help to identify poorly preserved samples and to then exclude inaccurate sulphur isotope measurements.

Acknowledgements We would like to thank the Max-Planck Society for funding and Christin Ellenberger from the Veterinary Pathology of the University of Leipzig for providing modern animal samples. We would also like to thank Oliver Craig for suggestions to confirm the reliability of our isotopic measurement with conventional methods, and Christine Lehn, who suggested the idea of chondroitin sulphate in the modern bone collagen samples. We would also like to thank the two reviewers for very helpful suggestions and comments on our manuscript.

\section{Appendix}

Collagen as a protein is organised as triple helix, containing two $\alpha 1$ chains and one $\alpha 2$ chain of amino acids. The three chains are connected by hydrolysed bonds. The sequences of the amino acids are inherited genetically. Single amino acids are bonded by amide bonds (or peptide bonds). During the reaction of single amino acids to dipeptides water is released. Therefore, the molecular mass of each amino acid within a chain is the amino acid mass subtracted by the molecular mass of water. The number of residues of each amino acid within a chain (for data from DNA sequences) was obtained. For the theoretical calculation of the amount of carbon, nitrogen, and sulphur, the amount of each element in all amino acids was calculated either by molecular mass or as a percentage (see Table 8). We calculated, for each amino acid, the weight percentage of all of the constituent elements and our detailed calculations are shown in Table 9. Published amino acid sequences from species were either presented as a percentage of each amino acid or as the number of residues per 1,000 amino acids (which was then recalculated to percentages). In these cases, the amount of each element was only calculated as a percent of the complete molecule and there is no differentiation between single chains of the collagen molecule. The final percentages therefore represent only a theoretical collagen molecule and post-translational modifications are not taken into account.

The obtained weight percent of all elements of a specimen is further used to calculate atomic ratios by dividing the weight percent multiplied by the quotient of the elemental weights. The resulting ratio represents the atomic ratio of the particular elements.

Table 8 Calculation of amounts of containing chemical elements, by residue and percentage of the amino acid

\begin{tabular}{|c|c|c|c|c|c|c|c|c|c|c|c|c|}
\hline \multirow[b]{2}{*}{ Amino acid } & & \multicolumn{5}{|c|}{ Number of residue of element } & \multirow[b]{2}{*}{ Molecular weight $\left(\mathrm{g} \times \mathrm{mol}^{-1}\right)$} & \multicolumn{5}{|c|}{ Percentage of element } \\
\hline & & $\mathrm{C}$ & $\mathrm{N}$ & $\mathrm{O}$ & $\mathrm{H}$ & $\mathrm{S}$ & & $\mathrm{C} \%$ & N\% & $\mathrm{O} \%$ & $\mathrm{H} \%$ & $\mathrm{~S} \%$ \\
\hline Hydroxyproline & OH-Pro & 5 & 1 & 3 & 9 & 0 & 131.13 & 45.8 & 10.7 & 36.6 & 6.9 & 0.0 \\
\hline Aspartic acid & Asp & 4 & 1 & 4 & 5 & 0 & 131.09 & 36.7 & 10.7 & 48.8 & 3.8 & 0.0 \\
\hline Threonine & Thr & 4 & 1 & 3 & 9 & 0 & 119.12 & 40.3 & 11.8 & 40.3 & 7.6 & 0.0 \\
\hline Serine & Ser & 3 & 1 & 3 & 7 & 0 & 105.09 & 34.3 & 13.3 & 45.7 & 6.7 & 0.0 \\
\hline Glutamic acid & Glu & 5 & 1 & 4 & 9 & 0 & 147.13 & 40.8 & 9.5 & 43.5 & 6.2 & 0.0 \\
\hline Proline & Pro & 5 & 1 & 2 & 9 & 0 & 115.13 & 52.2 & 12.2 & 27.8 & 7.9 & 0.0 \\
\hline Glycine & Gly & 2 & 1 & 2 & 5 & 0 & 75.07 & 32.0 & 18.7 & 42.6 & 6.7 & 0.0 \\
\hline Alanine & Ala & 3 & 1 & 2 & 7 & 0 & 89.09 & 40.4 & 15.7 & 35.9 & 7.9 & 0.0 \\
\hline Cysteine & Cys & 3 & 1 & 2 & 7 & 1 & 121.16 & 29.7 & 11.6 & 26.4 & 5.8 & 26.5 \\
\hline Valine & Val & 5 & 1 & 2 & 11 & 0 & 117.15 & 51.3 & 12.0 & 27.3 & 9.5 & 0.0 \\
\hline Methionine & Met & 5 & 1 & 2 & 11 & 1 & 149.21 & 40.2 & 9.4 & 21.4 & 7.4 & 21.5 \\
\hline Isoleucine & Ile & 6 & 1 & 2 & 13 & 0 & 131.17 & 54.9 & 10.7 & 24.4 & 10.0 & 0.0 \\
\hline Leucine & Leu & 6 & 1 & 2 & 13 & 0 & 131.17 & 54.9 & 10.7 & 24.4 & 10.0 & 0.0 \\
\hline Tyrosine & Tyr & 9 & 1 & 3 & 11 & 0 & 181.19 & 59.7 & 7.7 & 26.5 & 6.1 & 0.0 \\
\hline Phenylalanine & Phe & 9 & 1 & 2 & 11 & 0 & 165.19 & 65.4 & 8.5 & 19.4 & 6.7 & 0.0 \\
\hline Hydroxylysine & OH Lys & 6 & 2 & 3 & 14 & 0 & 162.19 & 44.4 & 17.3 & 29.6 & 8.7 & 0.0 \\
\hline Lysine & Lys & 6 & 2 & 2 & 14 & 0 & 146.19 & 49.3 & 19.2 & 21.9 & 9.7 & 0.0 \\
\hline Histidine & His & 6 & 3 & 2 & 9 & 0 & 155.16 & 46.4 & 27.1 & 20.6 & 5.8 & 0.0 \\
\hline Arginine & Arg & 6 & 4 & 2 & 14 & 0 & 174.20 & 41.4 & 32.2 & 18.4 & 8.1 & 0.0 \\
\hline Asparagine & Asn & 4 & 2 & 3 & 8 & 0 & 132.12 & 36.4 & 21.2 & 36.3 & 6.1 & 0.0 \\
\hline Glutamin & Gln & 5 & 2 & 3 & 10 & 0 & 146.15 & 41.1 & 19.2 & 32.8 & 6.9 & 0.0 \\
\hline
\end{tabular}




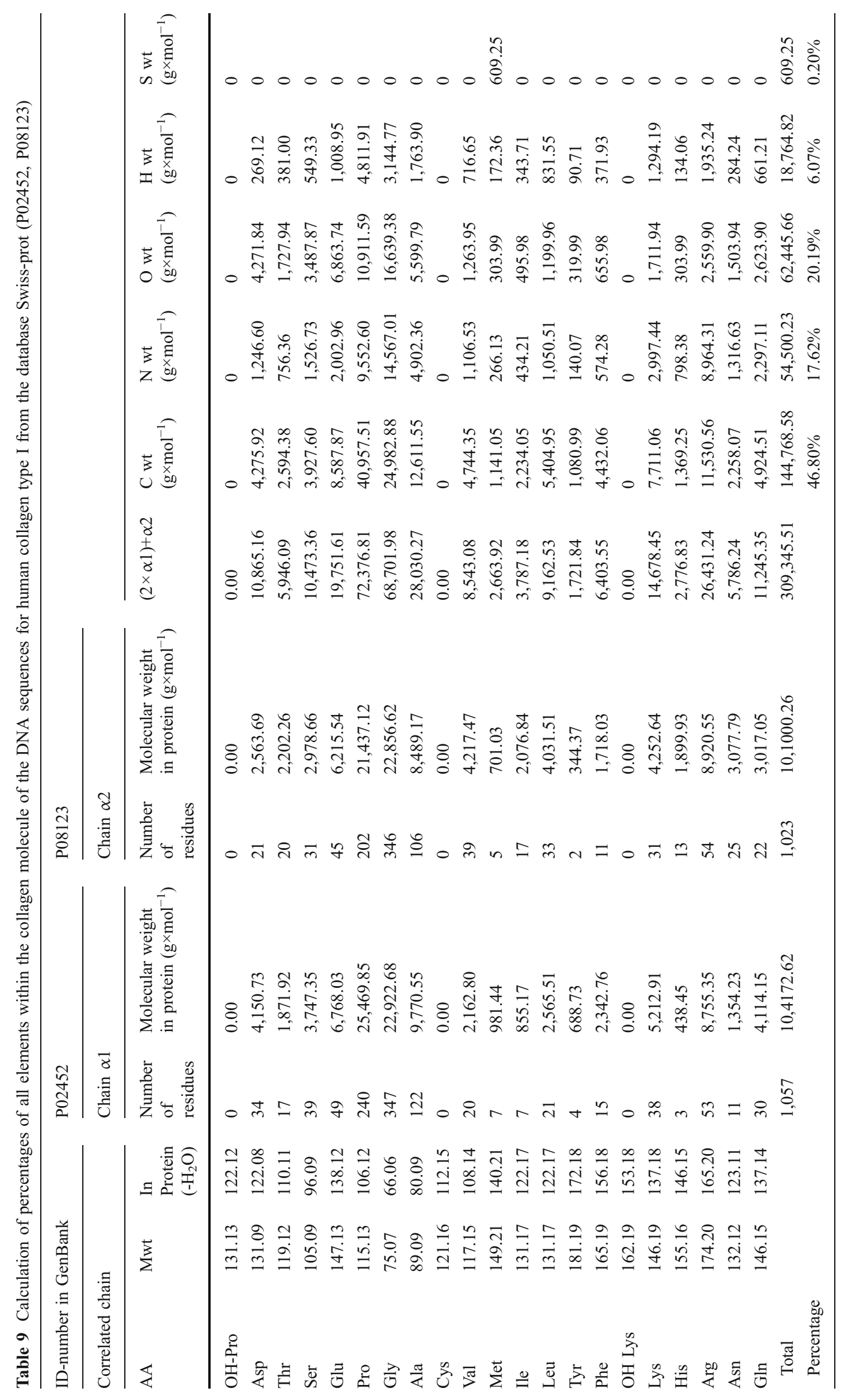




\section{References}

Ambrose SH (1990) Preparation and characterization of bone and tooth collagen for isotopic analysis. J Archaeol Sci 17:431451

Ambrose SH, Norr L (1993) Experimental evidence for the relationship of the carbon isotope ratios of whole diet and dietary protein to those of bone collagen and carbonate. In: Ambrose SH, Norr L (eds) Prehistoric human bone - archaeology at the molecular level. Springer, Berlin, pp 1-38

Barrett J, Johnstone C, Harland J, Van Neer W, Ervynck A, Makowiecki D, Heinrich D, Hufthammer AK, Enghoff IB, Amundsen C, Christiansen JS, Jones AKG, Locker A, Hamilton-Dyer S (2008) Detecting the medieval cod trade: a new method and first results. J Archaeol Sci 35:850-861

Bornstein P, Traub W (1979) The chemistry and biology of collagen. In: Bornstein P, Traub W (eds) The proteins, 3. Academic Press, San Diego, pp 411-632

Bracho GE, Haard NF (1995) Purification, characterization, and radiolabeling of lingcod (Ophiodon Elongatus) skin type I collagen. J Food Biochem 19:285-297

Burger M, Sherman BS, Sobel AE (1962) Observations of the Influence of chondroitin sulphate on the rate of bone repair. $\mathrm{J}$ Bone J Surg 44B:675-687

Cantoni GL (1975) Biological methylation: selected aspects. Annu Rev Biochem 44:435-451

Coleman M (2004) Data corrections for mass-spectrometer analysis of $\mathrm{SO}_{2}$. In: de Groot PA (ed) Handbook of stable isotope analytical techniques. Elsevier, Amsterdam, pp 957-970

Coplen TB, Krouse RH (1998) Sulphur isotope data consistency improved. Nature 392:32

Craig OE, Ross R, Andersen SH, Milner N, Bailey GN (2006) Focus: sulphur isotope variation in archaeological marine fauna from northern Europe. J Archaeol Sci 33:1642-1646

De Maesschalck R, Jouan-Rimbaud D, Massart DL (2000) The Mahalanobis distance. Chemometr Intell Lab Syst 50:1-18

DeNiro MJ (1985) Postmortem preservation and alteration of in vivo bone collagen isotope ratios in relation to palaeodietary reconstruction. Nature 317:806-809

DeNiro MJ, Weiner S (1988) Chemical, enzymatic and spectroscopic characterization of "collagen" and other organic fractions from prehistoric bones. Geochim Cosmochim Acta 52:2197-2206

Dungworth G, Schwartz AW, de van Leemput L (1976) Composition and racemization of amino acids in mammoth collagen determined by gas and liquid chromatography. Comp Biochem Physiol Part B: Biochem Mol Biol 53:473-480

Dziewiatkowski DD (1962) Sulfur. In: Comar CL, Bronner F (eds) Mineral metabolism: an advanced treatise. Academic Press, New York, pp 175-220

Eastoe JE (1955) The amino acid composition of mammalian collagen and gelatin. Biochem J 61:589-600

Eastoe JE (1957) The amino acid composition of fish collagen and gelatin. Biochem J 65:363-368

Eastoe JE, Leach AA (1958) A survey of recent work on the amino acid composition of vertebrate collagen and gelatin. In: Stainsby $\mathrm{G}$ (ed) Recent advances in gelatin and glue research. Proceedings of a conference sponsored by The British Gelatine and Glue Research Association held at the University of Cambridge, 1-5 July 1957. Pergamon Press, London, pp 173-182

Eastoe JE, Martens P, Thomas NR (1973) The amino-acid composition of human hard tissue collagens in osteogenesis imperfecta and dentinogenesis imperfecta. Calcif Tissue Int 12:91-100

Finkelstein JD, Martin JJ (1984) Methionine metabolism in mammals. Distribution of homocysteine between competing pathways. J Biol Chem 259:9508-9513
Finkelstein JD, Martin JJ, Harris BJ (1988) Methionine metabolism in mammals. The methionine-sparing effect of cystine. J Biol Chem 263:11750-11754

Francois CJ, Glimcher MJ (1967) The isolation and amino acid composition of the [alpha] chains of chicken-bone collagen. Biochim Biophys Acta - Protein Structure 133:91-96

Fry B, Silva SR, Kendall C, Anderson RK (2002) Oxygen isotope corrections for online $\delta^{34} \mathrm{~S}$ analysis. Rapid Commun Mass Spectrom 16:854-858

Giesemann AJH, Norman AL, Krouse HR, Brand WA (1994) On-line sulfur-isotope determination using an elemental analyzer coupled to a mass spectrometer. Anal Chem 66:2816-2819

Gomez-Guillen MC, Turnay J, Fernandez-Diaz MD, Ulmo N, Lizarbe MA, Montero P (2002) Structural and physical properties of gelatin extracted from different marine species: a comparative study. Food Hydrocolloids 16:25-34

Ho T (1966) The isolation and amino acid composition of the bone collagen in Pleistocene mammals. Comp Biochem Physiol $18: 353-358$

Ho T (1967) The amino acids of bone and dentine collagens in Pleistocene mammals. Biochim Biophys Acta 133:568-573

Jongjareonrak A, Benjakul S, Visessanguan W, Tanaka M (2005) Isolation and characterization of collagen from bigeye snapper (Priacanthus macracanthus) skin. J Sci Food Agric 85:12031210

Katafuchi M, Matsuura T, Atsawasuwan P, Sato H, Yamauchi M (2007) Biochemical characterization of collagen in alveolar mucosa and attached gingiva of pig. Connect Tissue Res 48:85-92

Kawaguchi T (1993) Chemical nature of collagen in the dermis of the lamprey, Entosphenus japonicus. Comp Biochem Physiol Part B: Biochem Mol Biol 104:559-566

Kester CL, Rye RO, Johnson CA, Schwartz C, Holmes C (2001) Online sulfur isotope analysis of organic material by direct combustion. Isot Environ Health Stud 37:53-65

Kimura S (1983) Vertebrate skin type I collagen: comparison of bony fishes with lamprey and calf. Comp Biochem Physiol B 74:525528

Kimura S (1992) Wide distribution of the skin type I collagen [alpha]3 chain in bony fish. Comp Biochem Physiol B 102:255-260

Kimura S, Ohno Y (1987) Fish type I collagen: tissue-specific existence of two molecular forms, $(\alpha 1)_{2} \alpha_{2}$ and $\alpha 1 \quad \alpha 2 \quad \alpha 3$, in Alaska pollack. Comp Biochem Physiol 88B:409-413

Kimura S, Miyauchi Y, Uchida N (1991) Scale and bone type I collagens of carp (Cyprinus carpio). Comp Biochem Physiol B 99:473-476

Kittiphattanabawon P, Benjakul S, Visessanguan W, Nagai T, Tanaka M (2005) Characterisation of acid-soluble collagen from skin and bone of bigeye snapper (Priacanthus tayenus). Food Chem $89: 363-372$

Leach BF (2003) The use of multiple isotope signatures in reconstructing prehistoric human diet from archaeological bone from the Pacific and New Zealand. N Z J Archaeol 23(2001):31-98

Li H, Liu BL, Gao LZ, Chen HL (2004) Studies on bullfrog skin collagen. Food Chem 84:65-69

Liu H, Li D, Guo S (2007) Studies on collagen from the skin of channel catfish (Ictalurus punctaus). Food Chem 101:621-625

Matsui R, Ishida M, Kimura S (1991) Characterization of an alpha 3 chain from the skin type I collagen of chum salmon (Oncoorhynchus keta). Comp Biochem Physiol B 99:171-174

Matsumura T (1973) Shape, size and amino acid composition of collagen fibril of the starfish Asterias amurensis. Comp Biochem Physiol B1 44:1197-1202

Miller EJ (1984) Chemistry of the collagens and their distribution. In: Piez KA, Reddi AH (eds) Extracellular matrix biochemistry. Elsevier, New York, pp 41-81 
Miller EJ, Rhodes KR (1982) Preparation and characterization of the different types of collagen. In: Cunningham LW, Frederiksen DW (ed) Methods in enzymology. Academic Press, pp 33-64

Mizuta S, Miyagi T, Yoshinaka R (1998) Characterization of a major alpha component of collagen from muscle of antarctic krill Euphausa superba. Comp Biochem Physiol B 120:597-604

Morrison J, Fourel F, Churchman D (2000) Isotopic sulphur analysis by continuous flow Isotope ratio mass spectrometry (CF-IRMS). Application Note 509

Nagai T, Araki Y, Suzuki N (2002) Collagen of the skin of ocellate puffer fish (Takifugu rubripes). Food Chem 78:173-177

Nawrot CF, Campbell DJ (1977) A chromatographic study of the relative affinities of rat bone and skin collagen alpha1 chains for hydroxyapatite. J Dent Res 56:1017-1022

Neumann RE (1949) The amino acid composition of gelatins, collagens and elastins from different sources. Arch Biochem 24:289-298

Nishimoto M, Sakamoto R, Mizuta S, Yoshinaka R (2005) Identification and characterization of molecular species of collagen in ordinary muscle and skin of the Japanese flounder Paralichthys olivaceus. Food Chem 90:151-156

Öbrink B, Laurent TC, Crlsson B (1975) The Binding of Chondroitin Sulphate to Collagen. FEBS Lett 56:166-169

Ogawa M, Portier RJ, Moody MW, Bell J, Schexnayder MA, Losso JN (2004) Biochemical properties of bone and scale collagens isolated from the subtropical fish black drum (Pogonia cromis) and sheepshead seabream (Archosargus probatocephalus). Food Chem 88:495-501

Piez KA (1976) Primary structure. In: Ramachandran GN, Reddi AH (eds) Biochemistry of collagen. Plenum Press, New York, pp 1-44

Piez KA (1984) Molecular and aggregate structures of the collagens. In: Piez KA, Reddi AH (eds) Extracellular matrix biochemistry. Elsevier, New York, pp 1-39

Piez KA, Eigner EA, Lewis MS (1963) The chromatographic separation and amino acid composition of the subunits of several collagens. Biochemistry 2:58-66

Privat KL, O'Connell TC, Hedges REM (2007) The distinction between freshwater- and terrestrial-based diets: methodological concerns and archaeological applications of sulphur stable isotope analysis. J Archaeol Sci 34:1197-1204

Ramachandran GN, Doyle BB, Bloot ER (1968) Single-chain triple helical structure. Biopolymers 6:1771-1775

Ramshaw JA M, Werkmeister JA, Bremner HA (1988) Characterization of collagen type I from the skin of blue grenadier (Macruronus novaezelandiae). Arch Biochem Biophys 267:497-502

Reddi AH (1984) Extracellular matrix and development. In: Piez KA, Reddi AH (eds) Extracellular matrix biochemistry. Elsevier, New York, pp 375-412

Richards M, Hedges R (1999) Stable isotope evidence for similarities in the types of marine foods used by late mesolithic humans at sites along the Atlantic coast of Europe. J Archaeol Sci 26:717-722
Richards MP, Fuller BT, Hedges REM (2001) Sulphur isotopic variation in ancient bone collagen from Europe: implications for human palaeodiet, residence mobility, and modern pollutant studies. Earth Planet Sci Lett 191:185-190

Robinson JJ (1997) Comparative biochemical analysis of sea urchin peristome and rat tail tendon collagen. Comp Biochem Physiol B 117:307-313

Saito M, Takenouchi Y, Kunisaki N, Kimura S (2001) Complete primary structure of rainbow trout type I collagen consisting of alpha1(I)alpha2(I)alpha3(I) heterotrimers. Eur J Biochem 268:2817-2827

Sato K, Yoshinaka R, Sato M, Itoh Y, Shimizu Y (1988) Isolation of types I and $\mathrm{V}$ collagens from carp muscle. Comp Biochem Physiol B 90:155-158

Sato K, Yoshinaka R, Itoh Y, Sato M (1989) Molecular species of collagen in the intramuscular connective tissue of fish. Comp Biochem Physiol B 92:87-91

Schaedler JM, Krook L, Wootton JA, Hover B, Brodsky B, Naresh MD, Gillette DD, Madsen DB, Horne RH, Minor RR (1992) Studies of collagen in bone and dentin matrix of a Columbian mammoth (Late Pleistocene) of Central Utah. Matrix 12:297-307

Schneiders W, Reinstorf A, Ruhnow M, Rehberg S, Heineck J, Hinterseher I, Biewener A, Zwipp H, Rammelt S (2008) Effect of chondroitin sulphate on material properties and bone remodelling around hydroxyapatite/collagen composites. J Biomed Mater Res 85A:638-645

Seyer JM, Kang AH, Whittaker JN (1977) The characterization of type I and type III collagens from human peripheral nerve. Biochim Biophys Acta 492:415-425

Todhunter RJ, Wootton JA, Minor RR (1994) Structure of equine type I and type II collagen. Am J Vet Res 55:425-431

Ueda A, Krouse HR (1986) Direct conversion of sulphide and sulphate minerals to $\mathrm{SO}_{2}$ for isotope analyses. Geochem $\mathrm{J}$ 20:209-212

van Klinken G (1999) Bone collagen quality indicators for palaeodietary and radiocarbon measurement. J Archaeol Sci 26:687-695

Van Klinken GJ, Mook WG (1990) Preparative high-performance liquid chromatographic separation of individual amino acids derived from fossil bone collagen. Radiocarbon 32:155-164

Veis A (1984) Bones and teeth. In: Piez KA, Reddi AH (eds) Extracellular matrix biochemistry. Elsevier, New York, pp 329-374

Yata M, Yoshida C, Fujisawa S, Mizuta S, Yoshinaka R (2001) Identification and characterization of molecular species of collagen in fish skin. J Food Sci 66:247-251

Yun M, Mayer B, Taylor SW (2005) $\delta^{34}$ S measurements on organic materials by continuous flow isotope ratio mass spectrometry. Rapid Commun Mass Spectrom 19:1429-1436

Zhang Y, Liu W, Li G, Shi B, Miao Y, Wu X (2007) Isolation and partial characterization of pepsin-soluble collagen from the skin of grass carp (Ctenopharyngodon idella). Food Chem 103:906-912 